\title{
SUBSTITUIÇÃO DO SUBSTRATO COMERCIAL POR CASCA DE ARROZ CARBONIZADA PARA PRODUÇÃO DE MUDAS DE CAFEEIRO EM TUBETES NA PRESENÇA DE POLÍMERO HIDRORRETENTOR ${ }^{1}$
}

\author{
Replacement of the commercial substrate by carbonized rice husk in the coffee tree \\ seedlings production in tubes in the presence of hydroretentive polymer
}

\author{
Haroldo Silva Vallone ${ }^{2}$, Rubens José Guimarães ${ }^{3}$, Carlos Alberto Spaggiari Souza ${ }^{4}$, \\ Jacinto de Assunção Carvalho ${ }^{5}$, Rodrigo de Sousa Ferreira ${ }^{6}$, Sirlei de Oliveira ${ }^{7}$
}

\begin{abstract}
RESUMO
Com o objetivo de avaliar os efeitos da substituição do substrato comercial por casca de arroz carbonizada e da adição de polímero hidrorretentor no desenvolvimento de mudas de cafeeiro em tubetes de $120 \mathrm{~mL}$, conduziu-se este experimento no Setor de Cafeicultura da Universidade Federal de Lavras, no período de abril a novembro de 2002. Utilizou-se o delineamento experimental em blocos casualizados em esquema fatorial $(5 \times 2)$ com 4 repetições. A parcela foi composta por 13 tubetes, considerando-se úteis os 5 centrais. Os tratamentos estudados consistiram de 5 proporções de casca de arroz carbonizada em substituição ao substrato comercial $(0 \%, 25 \%, 50 \%, 75 \%$ e 100\%), com e sem a presença do polímero hidrorretentor, na dose fixa de $10 \mathrm{~kg} \mathrm{~m}^{-3}$ de substrato. A cultivar utilizada foi a Acaiá Cerrado, MG-1474. Pelos resultados obtidos, pode-se concluir que a substituição do substrato comercial por casca de arroz carbonizada, entre 60 e $70 \%$, proporciona maior desenvolvimento de mudas e em menor tempo e que a incorporação de polímero hidrorretentor na dose de $10 \mathrm{~kg} \mathrm{~m}^{-3}$ de substrato prejudica o desenvolvimento delas.
\end{abstract}

Termos para indexação: Polímero hidrorretentor, casca de arroz carbonizada, produção de mudas, café.

\begin{abstract}
With the purposes of verifying the effect of the replacement of the commercial substrate by carbonized rice husk and the addition of hydroretentive polymer on the development of coffee tree seedlings in $120 \mathrm{~mL}$ tubes, an experiment was conducted at the Coffee Culture Sector of the Universidade Federal de Lavras - UFLA, from April 2002 to November 2002. The experiment was set up according to a four-replicate randomized complete-block design, with a $5 \times 2$ factorial arrangement. Plots was comprised of 13 tubes, the five central ones considered as the useful experimental area. Treatments studied consisted of the five proportion of the replacement of the commercial substrate to carbonized rice husk $(0 \%, 25 \%, 50 \%, 75 \%$ and $100 \%$ of replacement) in the presence and absence of hydroretentive polymer. The cultivar employed was Acaiá Cerrado MG-1474. The results obtained enable to conclude that the replacing of commercial substrate for toasted rice coat between 60 and $70 \%$, confer greater increase in the seedlings in least time and the incorporation of hydroretentive polymer in dose of $10 \mathrm{~kg} \mathrm{~m}^{-3}$ in the substrate, damaging the growth of ones.
\end{abstract}

Index terms: Hydroretentive polymer, carbonized rice husk, coffee tree seedling production.

(Recebido para publicação em 3 de junho de 2003 e aprovado em 19 de agosto de 2003)

\section{INTRODUÇÃO}

A cafeicultura é reconhecida como uma atividade de grande importância econômica e social para o Brasil. A obtenção de mudas de cafeeiro de boa qualidade é um fator preponderante na implantação de uma lavoura produtiva e duradoura. Em razão de tal importância, vários trabalhos têm sido realizados no intuito de buscar a produção de mudas com qualidade superior e com baixos custos. Um item de suma impor-

\footnotetext{
1. Parte da dissertação apresentada àUniversidade Federal de Lavras/UFLA - Caixa Postal 37 - 37200-000 - Lavras, MG, pelo primeiro autor, para obtenção do grau de mestre em Agronomia, área de concentração Fitotecnia.

2. Engenheiro Agrônomo, estudante de doutorado em Fitotecnia - UFLA.

3. Engenheiro Agrônomo, Dr., Professor Adjunto, Departamento de Agricultura/UFLA.

4. Engenheiro Agrônomo, Dr., Pesquisador, CEPLAC, Linhares, ES.

5. Engenheiro Agrícola, Dr., Professor Adjunto, Departamento de Engenharia/UFLA

6. Estudante do curso de Agronomia da UFLA.

7. Engenheiro Agrônomo, estudante de mestrado em Fitotecnia - UFLA
} 
tância que é alvo de várias pesquisas é a composição de substratos para a produção de mudas em tubetes, insumo esse responsável por $38 \%$ do custo de produção das mudas (GUIMARÃES et al., 1998). Atualmente o substrato mais utilizado para produção em tubetes é constituído de casca de Pinus moída, compostada e enriquecida com nutrientes.

Campos (2002) afirma que para a produção de mudas em tubetes, o substrato merece especial atenção, pois um reduzido volume, geralmente $120 \mathrm{~mL}$, deverá dar suporte para o desenvolvimento da planta durante todo o período de sua formação, propiciando uma muda saudável, com bom desenvolvimento radicular e uma boa relação parte aérea/raiz.

O uso de substratos sem solo mineral tem sido apontado como alternativa para eliminar a necessidade do uso de biocidas, entre eles o brometo de metila, substância que contribui para a destruição da camada de ozônio e que, na agricultura, é utilizado para esterilização do solo (KÄMPF, 2002). A casca de arroz carbonizada vem sendo estudada em misturas de substratos para a produção de mudas e, segundo Minami (1995), possui forma floculada, é leve, de fácil manuseio, com grande capacidade de drenagem, $\mathrm{pH}$ levemente alcalino, baixa capacidade de retenção de umidade, rica em cálcio e potássio, livre de nematóides e patógenos devido ao processo de carbonização. Segundo Puchalski e Kämpf (2000), possui espaço de aeração superior a $42 \%$ e porosidade total acima de $80 \%$, características ideais para substratos utilizados em recipientes com pequeno volume. Klein et al. (2002), avaliando as alterações nas propriedades físico-hídricas de substratos comerciais, com a mistura de casca de arroz carbonizada em diferentes proporções, concluíram que a casca de arroz pode ser utilizada para otimizar as propriedades físico-hídricas de substratos hortícolas, melhorando a disponibilidade de água às plantas e a porosidade de aeração.

Uma técnica ainda muito pouco estudada é a adição de polímeros hidrorretentores como condicionadores hídricos de solo, visando a aumentar a capacidade de armazenamento de água em substratos para mudas, propiciando melhor qualidade. $\mathrm{O}$ polímero hidrorretentor é caracterizado pela capacidade de absorver e liberar água e nutrientes solúveis. A natureza do arranjo das moléculas confere a esse material uma forma granular, quando secos, e ao serem hidratados, os grânulos dilatam-se, transformando-se em partículas de gel (PREVEDELLO e
BALENA, 2000). Hüttermann et al. (1999) afirmam que no passado foram feitos estudos com adição de polímeros hidrorretentores no solo, avaliando a sobrevivência de árvores sob condições de seca, e alguns pesquisadores não observaram efeitos benéficos mensuráveis desse tipo de produto, e em outros casos, a incorporação desses polímeros foi prejudicial às árvores jovens.

Mendonça et al. (2002), estudando a produção de mudas de cafeeiro em tubetes com polímero hidrorretentor adicionado ao substrato comercial Plantmax, concluíram que esse produto não apresentou resultados satisfatórios para a produção de mudas de café, recomendando a condução de novos experimentos.

Com o presente trabalho teve-se como objetivo avaliar os efeitos da substituição do substrato comercial por casca de arroz carbonizada e da adição de polímero hidrorretentor no desenvolvimento de mudas de cafeeiro em tubetes de $120 \mathrm{~mL}$.

\section{MATERIAL E MÉTODOS}

O experimento foi instalado no Setor de Cafeicultura do Departamento de Agricultura da Universidade Federal de Lavras - UFLA, localizada no sul do Estado de Minas Gerais, no período de abril a novembro de 2002. O delineamento experimental utilizado foi o de blocos casualizados (DBC), em esquema fatorial $\left(\begin{array}{lllll}5 & \mathrm{x} & 2\end{array}\right)$ com 4 repetições, totalizando 10 tratamentos e 40 parcelas. A parcela foi composta por 13 tubetes, sendo 5 úteis. Os tratamentos constaram de 5 proporções de casca de arroz carbonizada em substituição ao substrato comercial $(0 \%, 25 \%, 50 \%, 75 \%$ e $100 \%)$, com e sem a presença do polímero hidrorretentor, na dose de 10 $\mathrm{kg} \mathrm{\textrm {m } ^ { - 3 }}$ de substrato (recomendação do fabricante). Os substratos foram preparados misturando os dois componentes nas diferentes proporções, adicionando o fertilizante de liberação lenta (450 gramas $\mathrm{m}^{-3}$ de substrato) e o polímero hidrorretentor. Em seguida, procederam-se à homogeneização dos substratos e ao enchimento dos tubetes. O transplantio foi feito 99 dias após o semeio no germinador, estando as plântulas no estádio de "palito de fósforo".

Os recipientes utilizados foram tubetes de polietileno com capacidade de $120 \mathrm{~mL}$, com formato cônico, contendo cinco estrias internas, $3,7 \mathrm{~cm}$ de diâmetro interno da abertura superior, $0,8 \mathrm{~cm}$ de diâmetro interno da abertura inferior e $14 \mathrm{~cm}$ de altura.

Ciênc. agrotec., Lavras, v. 28, n. 3, p. 593-599, maio/jun., 2004 
O substrato comercial utilizado foi Plantmax Hortaliças ht, constituído à base de casca de pinus compostada, vermiculita e turfa processada e enriquecida. O polímero hidrorretentor utilizado foi o de marca comercial Hydrosolo, constituído de cadeias poliméricas, micronutrientes $(\mathrm{Cu}, \mathrm{Zn}, \mathrm{Mo}$ e $\mathrm{Fe})$ e bicarbonatos. A fertilização dos substratos foi feita utilizando-se o fertilizante de liberação lenta Osmocote, formulação 15-10-10 + micronutrientes. A cultivar utilizada foi a Acaiá Cerrado, MG - 1474. A germinação foi realizada em germinador de areia e o transplantio foi feito quando as plântulas atingiram o estádio de "palito de fósforo".

$\mathrm{O}$ experimento foi encerrado quando todas as parcelas apresentavam pelo menos $80 \%$ das plantas úteis com o estádio mínimo para comercialização, isto é, três pares de folhas verdadeiras. As características avaliadas foram: a) tempo para atingir o ponto comercial em dias, a partir do transplantio, ou seja, assim que cada parcela alcançava o ponto de comercialização, obtinha-se o tempo gasto. Porém, esperou-se que todas as parcelas atingissem esta condição para, só então, proceder às demais avaliações; b) altura da muda em centímetros; c) diâmetro do caule, na região do colo em milímetros; d) área foliar em centímetros quadrados por planta, estima- da com base na metodologia proposta por Huerta (1962); e) massa seca do sistema radicular e da parte aérea, em gramas por parcela de cinco plantas e f) relação entre as massas secas da parte aérea e do sistema radicular.

\section{RESULTADOS E DISCUSSÃO}

Foram observadas diferenças significativas para o efeito de porcentagem de substituição do substrato comercial em todas as características, exceto diâmetro do caule. Com relação ao efeito da adição de polímero hidrorretentor, diferenças significativas foram observadas para as características tempo para formação de mudas comerciais, altura da muda, MSPA, MSSR e área foliar. A interação entre \% de substituição do substrato comercial $\mathrm{x}$ presença de polímero não revelou efeito significativo para nenhuma característica avaliada, significando que o comportamento das mudas em cada substrato não depende da presença do polímero hidrorretentor.

As médias observadas para tempo de formação de mudas comerciais, altura, massa seca da parte aérea e do sistema radicular e área foliar de mudas de cafeeiro na presença e ausência de polímero hidrorretentor são apresentadas na Tabela 1 .

TABELA 1 - Médias de tempo de formação, altura, massa seca da parte aérea e do sistema radicular e área foliar de mudas de cafeeiro em função da presença de polímero hidrorretentor. UFLA, Lavras, MG, 2003.

\begin{tabular}{cccccc}
\hline $\begin{array}{c}\text { Polímero } \\
\text { Hidrorretentor }\end{array}$ & $\begin{array}{c}\text { Tempo } \\
(\mathbf{d i a s})\end{array}$ & $\begin{array}{c}\text { Altura } \\
(\mathbf{c m})\end{array}$ & $\begin{array}{c}\text { MSPA* } \\
(\mathbf{g})\end{array}$ & $\begin{array}{c}\text { MSSR* } \\
(\mathbf{g})\end{array}$ & $\begin{array}{c}\text { Área foliar } \\
\left(\mathbf{c m}^{2}\right)\end{array}$ \\
\hline Sem & $94.25 \mathrm{a}$ & $14.84 \mathrm{a}$ & $5.63 \mathrm{a}$ & $1.75 \mathrm{a}$ & $176.39 \mathrm{a}$ \\
Com & $96.85 \mathrm{~b}$ & $13.50 \mathrm{~b}$ & $4.85 \mathrm{~b}$ & $1.57 \mathrm{~b}$ & $153.83 \mathrm{~b}$ \\
\hline
\end{tabular}

Médias seguidas pela mesma letra não diferem significativamente pelo teste $\mathrm{F}$ a $5 \%$ de probabilidade.

*As médias apresentadas se referem a gramas por parcela de cinco plantas. 
A ausência de polímero propiciou a formação de mudas em menor tempo, embora a diferença alcançada, cerca de 2,6 dias, não traduza, na prática, em grandes benefícios para a atividade. As mudas produzidas na ausência de polímero foram superiores quanto à altura e à área foliar. Esses resultados concordam com os obtidos por Mendonça et al. (2002) e Ferreira et al. (2002) que, trabalhando com mudas de cafeeiro em substratos contendo polímero hidrorretentor, concluíram que a presença do mesmo reduziu a altura e a área foliar das mudas. O estudo de regressão para o tempo de formação de mudas em função da porcentagem de substituição do substrato comercial está representado na Figura 1. Observa-se que o ciclo de produção é reduzido, à medida que se aumenta a porcentagem de substituição do substrato comercial pela casca de arroz carbonizada, seguindo uma tendência linear. Neste estudo, a diferença entre os extremos ficou em torno de sete dias, o que é considerado benéfico para a produção de mudas de cafeeiro.

Para altura de mudas, o estudo de regressão em função da proporção de substrato comercial e casca de arroz carbonizada mostrou uma tendência quadrática, alcançando o máximo em $61 \%$ de substituição do substrato comercial (Figura 2).

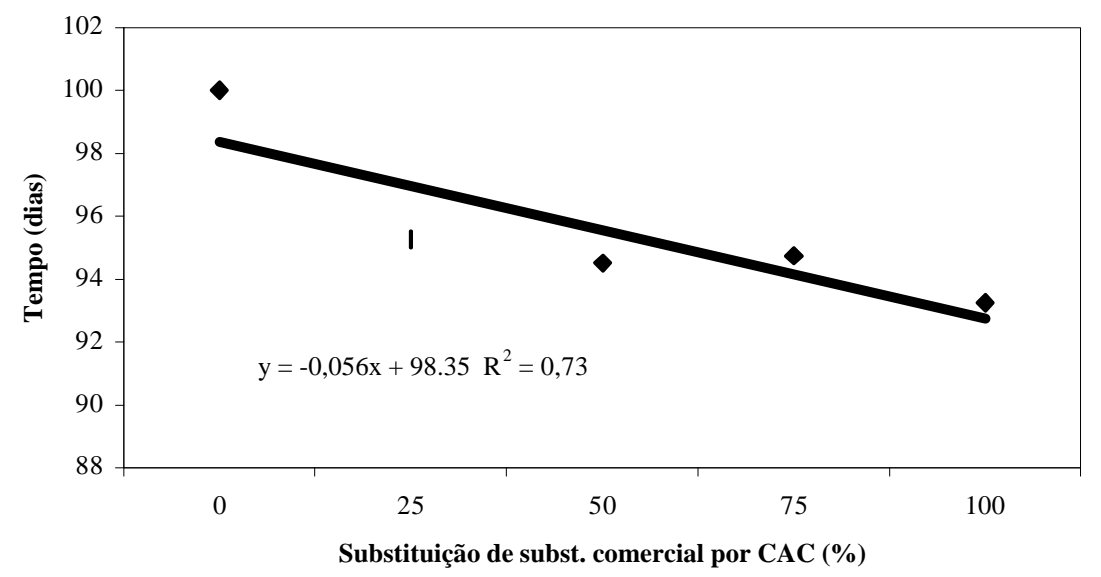

FIGURA 1 - Regressão para tempo de formação de mudas de cafeeiro em função da \% de substituição do substrato comercial. UFLA, Lavras, MG, 2003.

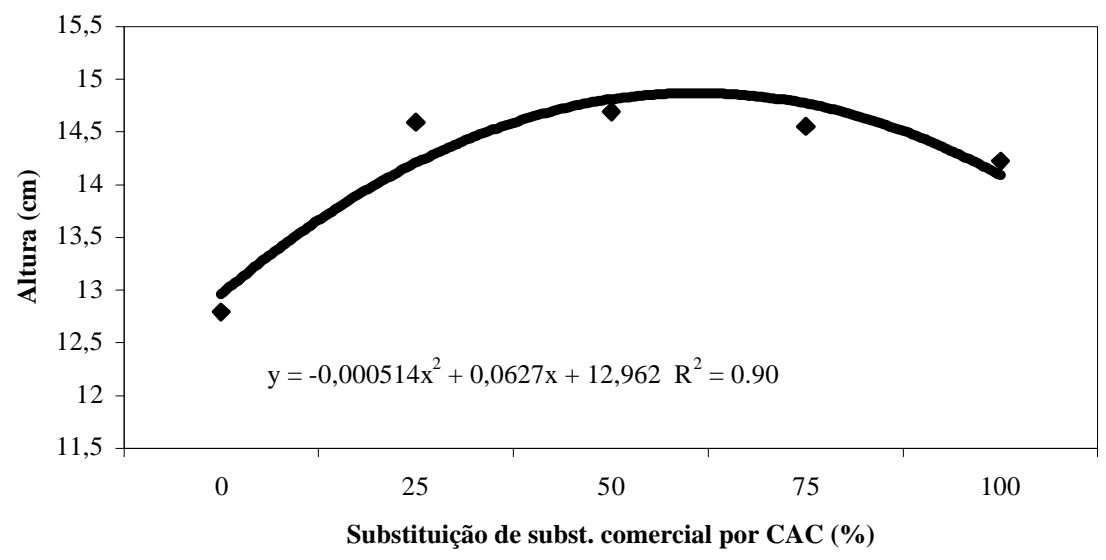

FIGURA 2 - Regressão para altura de mudas de cafeeiro em função da \% de substituição do substrato comercial. UFLA, Lavras, MG, 2003. 
A área foliar também foi influenciada significativamente pela substituição do substrato comercial por casca de arroz carbonizada, seguindo uma tendência quadrática, em que a área foliar máxima foi conseguida com 63,4\% de substrato comercial (Figura 3).

Na característica diâmetro do caule, não foram observados efeitos significativos tanto para porcentagem de substituição de substrato comercial por casca de arroz carbonizada quanto para presença de polímero hidrorretentor, indicando se tratar de uma característica pouco influenciável por propriedades do substrato. A média geral observada foi de $2,58 \mathrm{~mm}$.

As médias de massa seca da parte aérea (MSPA) e massa seca do sistema radicular (MSSR) em função da presença ou não de polímero hidrorretentor e o estudo de regressão em função da porcentagem de substrato comercial para as duas características encontram-se respectivamente na Tabela 1 e Figura 4. Observa-se que a presença de polímero nos substratos reduziu significativamente tanto a MSPA, quanto a MSSR das mudas de cafeeiro, enquanto o aumento da proporção de casca de arroz carbonizada também otimizou as duas características. A MSPA seguiu uma tendência quadrática, alcançando um máximo em $66,85 \%$ de substituição, enquanto a MSSR seguiu tendência linear, mostrando, mais uma vez, a eficiência da casca de arroz carbonizada na produção de mudas de cafeeiro. Assim, os resultados de MSPA, MSSR, altura, área foliar são coincidentes com os obtidos por Mendonça et al. (2002), possivelmente pelo fato de o polímero ter reduzido a porosidade de aeração, parâmetro importante no desenvolvimento de plantas, presente em menor quantidade no substrato comercial em relação aos com casca de arroz carbonizada (KLEIN et al., 2002).

Tanto a relação MSPA/MSSR quanto MSSR/MSPA não foram influenciadas significativamente pela adição de polímero hidrorretentor, obtendo-se médias de 3,21 e 0,32, respectivamente. A adição de polímero hidrorretentor reduziu tanto a MSPA quanto a MSSR, sem alterar a relação entre elas, prejudicando o desenvolvimento da muda como um todo.

Na Figura 5 é apresentado o estudo de regressão para relação MSPA/MSSR em função da substituição do substrato comercial por casca de arroz carbonizada. Observa-se uma tendência linear de redução na relação entre a parte aérea e o sistema radicular, isto é, à medida que se aumentava a proporção de casca de arroz carbonizada, diminuía-se a discrepância entre o desenvolvimento da parte aérea em relação ao do sistema radicular.

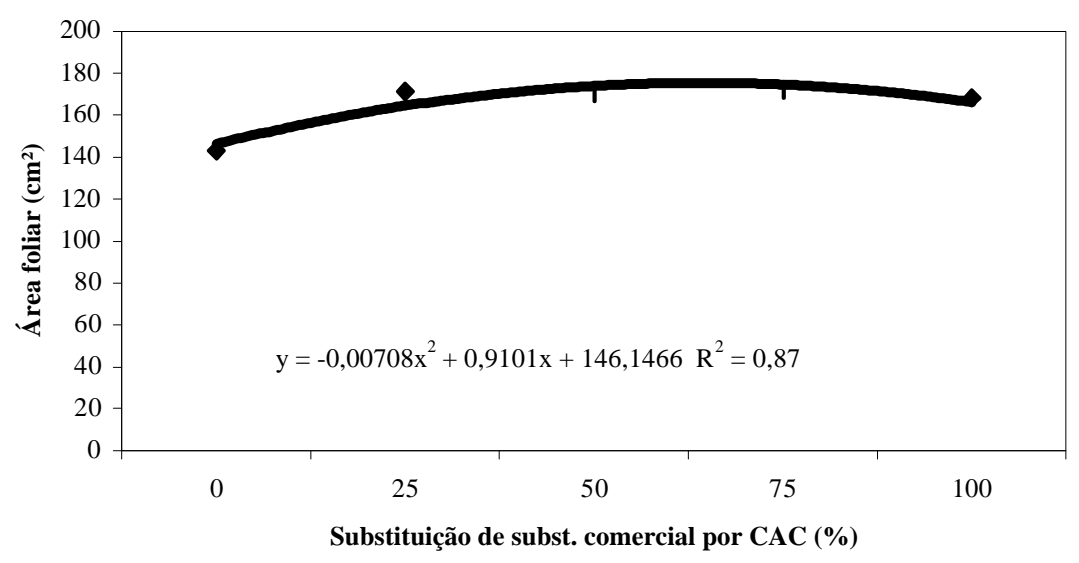

FIGURA 3 - Regressão para área foliar de mudas de cafeeiro em função de \% de substrato comercial. UFLA, Lavras, MG, 2003. 


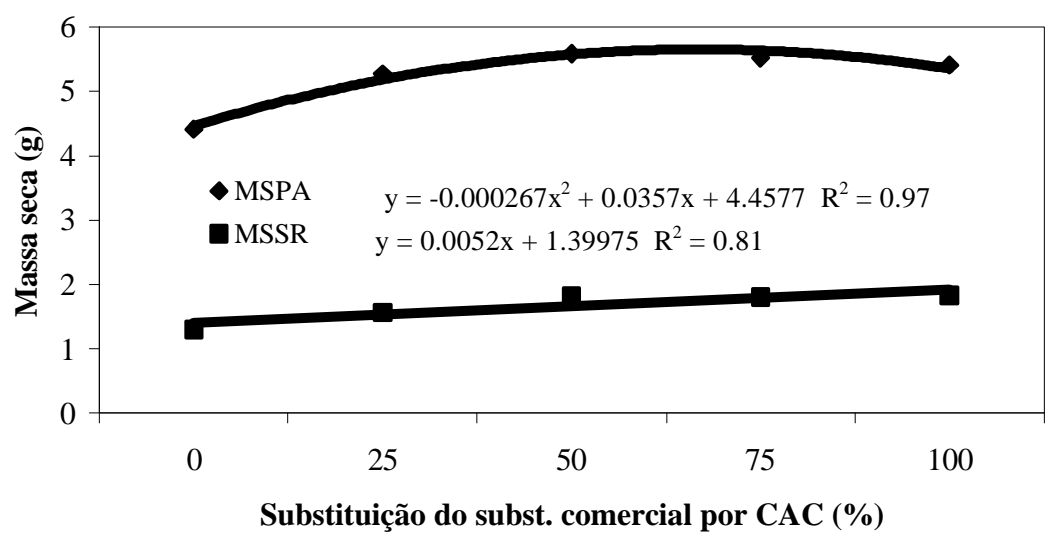

FIGURA 4 - Regressão para MSPA e MSSR de mudas de cafeeiro em função de \% de substrato comercial. UFLA, Lavras, MG, 2003.

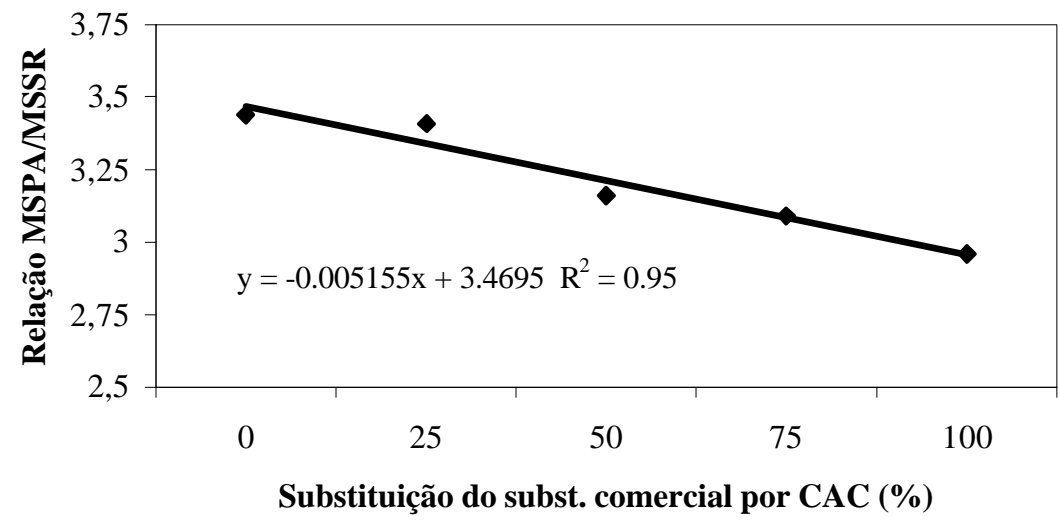

FIGURA 5 - Regressão para relação MSPA/MSSR de mudas de cafeeiro em função da proporção de substrato comercial. UFLA, Lavras, MG, 2003.

Kainuma et al. (2001) consideram como ideal a relação MSPA/MSSR entre 4 e 7 , porém, trabalharam com mudas apresentando 5 pares de folhas. Todavia, para a determinação da relação ideal entre parte aérea e sistema radicular, seriam necessários experimentos que avaliassem o desenvolvimento no campo de mudas com diferentes relações entre parte aérea e sistema radicular.

\section{CONCLUSÕES}

A incorporação de polímero hidrorretentor na dose de $10 \mathrm{~kg} \mathrm{~m}^{-3}$ de substrato aumenta o tempo necessário para a formação de mudas de cafeeiro e prejudica o desenvolvimento delas, não sendo, portanto, indicado para essa atividade.

A substituição de substrato comercial por casca de arroz carbonizada, entre 60 e $70 \%$, proporciona maior desenvolvimento de mudas e em menor tempo.

\section{REFERÊNCIAS BIBLIOGRÁFICAS}

CAMPOS, K. P. Desenvolvimento de mudas de cafeeiro (Coffea arabica L.) produzidas em diferentes substratos, fertilizações e tamanhos de tubetes. 2002. 90 p. Dissertação (Mestrado em Fitotecnia) - Universidade Federal de Lavras, Lavras, 2002. 
FERREIRA, R. de S.; VALLONE, H. S.; GUIMARÃES, R. J.; MELO, L. Q. de; CARVALHO, J. de A. Efeito de poliacrilato superabsorvente no desenvolvimento inicial do cafeeiro (Coffea arabica L.) em casa de vegetação sob diferentes níveis de déficit hídrico. In: CONGRESSO BRASILEIRO DE PESQUISAS CAFEEIRAS, 28., 2002, Caxambú. Trabalhos apresentados... Rio de Janeiro: MA/PROCAFÉ, 2002. p. 202-204.

GUIMARÃES, P. T. G.; ANDRADE NETO, A. de; BELLINI JÚNIOR, O.; ADÃO, W. A.; SILVA, E. M. da. Produção de mudas de cafeeiros em tubetes. Informe Agropecuário, Belo Horizonte, v. 19, n. 193, p. 98108, 1998.

HUERTA, S. A. Comparación de métodos de laboratório y de campo, para medir el área foliar del cafeto. Cenicafé, Caldas, v. 13, n. 1, p. 33-42, ene./mar. 1962.

HÜTTERMANN, A.; ZOMMORODI, M.; REISE, K. Addition of hydrogels to soil for prolonging the survival of Pinus halepensis seedlings subjected to drougth. Soil \& Tillage Research, Amsterdam, v. 50, p. 195-304, 1999.

KAINUMA, R. H.; MIGLIORANZA, É.; FONSECA, É. P.; MONTANARI, E.; FRANCO, E. Qualidade de mudas de Coffea arabica desenvolvidas em diferentes substratos e doses de adubo de liberação lenta. In: SIMPÓSIO DE PESQUISA DOS CAFÉS DO BRASIL, 2., 2001, Vitória. Anais... Brasília: EMBRAPA-CAFÉ, 2001. CD-ROM.

KÄMPF, A. N. O uso de substrato em cultivo protegido no agronegócio brasileiro. In: FURLANI, A.
M. C. Caracterização, manejo e qualidade de substratos para produção de plantas. Campinas: Instituto Agronômico, 2002. p. 1-6. (Documentos IAC, 70).

KLEIN, V. A.; CAMARA, R. K.; SIMON, M. A.; DIAS, S. T. Casca de arroz carbonizada como condicionador de substrato. In: FURLANI, A. M. C. Caracterização, manejo e qualidade de substratos para produção de plantas. Campinas: Instituto Agronômico, 2002. p. 95. (Documentos IAC, 70).

MENDONÇA, C. M.; TEODORO, R. E. F.; LIMA, L. M. L. de; FERNANDES, D. L.; CORDEIRO, M. G.; NOVAES, Y. N. Produção de mudas de café (Coffea arabica L.) cv. Acaiá em tubetes com polímero hidroabsorvente adicionado ao substrato. In: SIMPÓSIO BRASILEIRO DE PESQUISA EM CAFEICULTURA IRRIGADA, 5., 2002, Araguari. Anais... Uberlândia: UFU, 2002. p. 167-171.

MINAMI, K. Produção de mudas de alta qualidade em horticultura. São Paulo: Fundação Salim Farah Maluf, 1995. 128 p.

PREVEDELLO, C. L.; BALENA, S. O. Efeitos de polímeros hidrorretentores nas propriedades físicohídricas de dois meios porosos. Revista Brasileira de Ciência do Solo, Viçosa, v. 24, n. 2, p. 251-258, 2000.

PUCHALSKI, L. E. A.; KÄMPF, A. N. Efeito da altura do recipiente sobre a produção de mudas de hibiscus rosa sinensis L. em plugs. In: KÄMPF, A. N.; FERMINO, M. H. (Eds.). Substrato para plantas: a base da produção vegetal em recipientes. Porto Alegre: Genesis, 2000. p. 209-215. 